\title{
AUTOMATION SYSTEM FOR A BLYNK-CONTROLLED SHOOTING RANGE
}

\section{JULIÁN R. CAMARGO L, CÉSAR A. PERDOMO C H \& OSCAR D. FLÓREZ C}

Engineering Faculty, Universidad Distrital Francisco José de Caldas, Bogotá, Colombia

ABSTRACT
This paper presents the design of a prototype of an automation system for a shooting range that allows the control and
configuration of its main functions, being controlled from software designed in Blynk and installed in a mobile device
(Smartphone, Electronic Tablet, etc) with Android operating system, to eliminate or replace the process of shooting
different people from the end-user. Each one of the design, simulation and implementation processes of the scale
prototype will be presented in this document, which allows showing the versatility of the wireless sensor networks
topologies, in this case using ESP8266 reference WiFi modules, giving evidence of its ease of programming and
usefulness, and showing the advantages and applications offered by this type of technology.
KEYWORDS: Blynk, ESP8266, Guns, Internet of Things, PWM

Received: Jun 06, 2020; Accepted: Jun 26, 2020; Published: Aug 21, 2020; Paper Id.: IJMPERDJUN2020843

\section{INTRODUCTION}

In Colombia, one out of every three people possesses a legal weapon. Every day, on average, five people come to the Ministry of Defense's Department for the Control of the Arms, Ammunition, and Explosives Trade to buy a revolver, a gun, or a shotgun [1].

The statistics reveal a marked decrease in the tendency of Colombians to seek such protection, at least legally. There are 1,893,185 legally acquired small arms and light weapons in the country, although not all of them have a valid permit. Some of these arms are registered in the National Arms Registry (RNA). The other part corresponds to arms in the hands of the Public Forces (Army, Air Force, Navy, and Police). There are 1,283,996 arms in the Colombian National Arms Registry. The Armed Forces have a total of 609,189 small arms and light weapons [2].

Of the total number of RNA, only 336,764 weapons currently have a valid permit. Of the 567,959 arms in the hands of individuals, 230,563 have valid permits and of the 82,283 arms in the hands of legal entities, which are mainly private security services, 55,016 arms have valid permits [2], as can be seen in Figure 1. In addition to the military forces and individuals who wish to acquire a weapon because they consider security to be a fundamental factor in this decision, some civilians practice sports shooting (members of Shooting Clubs affiliated to the Colombian Shooting and Hunting Federation and arms collectors), who must comply with the legal requirements to carry out the aforementioned activities. 


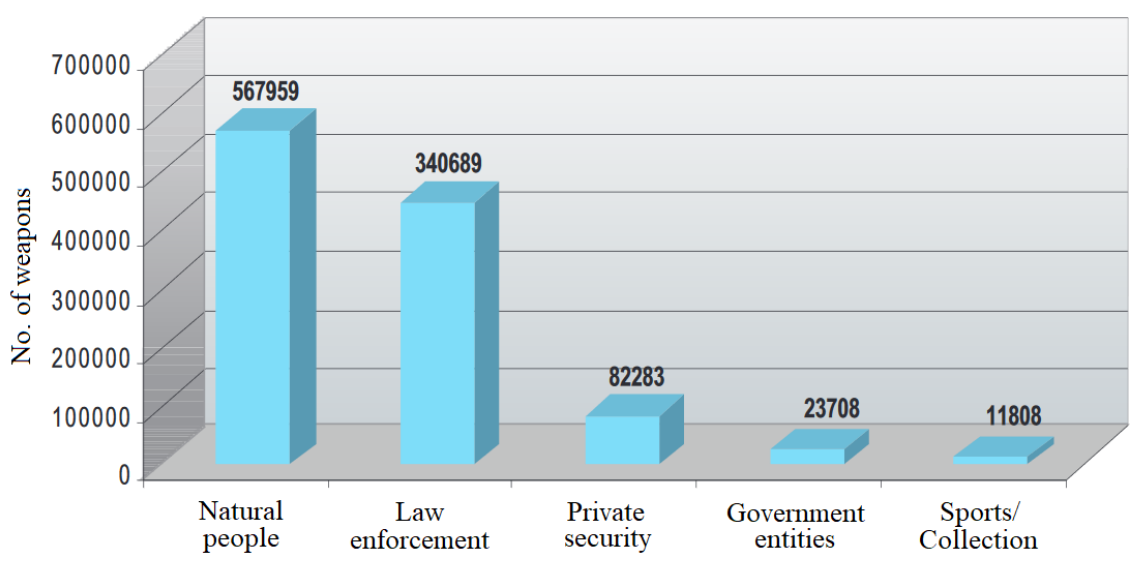

Figure 1: Who has the Guns in Colombia? [2].

The requirements that a person must meet to acquire a firearm are: to be over 25 years of age, not to have a criminal or disciplinary record, to undergo a psychometric examination, an analysis of personality traits and to take a specialized course in the handling of weapons [2], [3].

To take the weapons handling course, people must receive theoretical training and practical training at a shooting range currently, several companies provide this training service for the handling of arms, shooting ranges dedicated to sport shooting, and shooting ranges of the Colombian Military Forces (National Army Shooting School, Tolemaida Olympic Polygon, etc.). Hence the importance of having an automated, reliable system that can be completely controlled and configured by the end-user.

\section{METHODOLOGY}

\section{System Overview}

The general block diagram of the system proposed for the configuration and automation of the shooting range is shown in Figure 2.

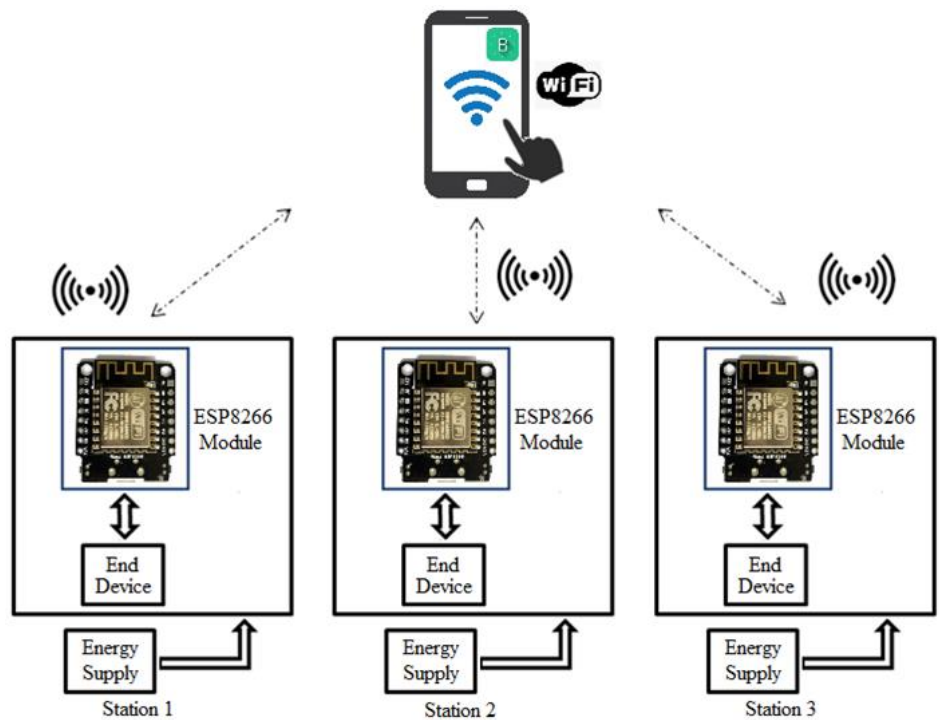

Figure 2: General Block Diagram.

The system consists of three stations, each of which includes an ES8266P [4]-[6] module that handles the WiFi communication and the transfer of commands and functions (control) of the end device. The process is centralized in a 
smartphone that has installed the application developed in Blynk [7], this is in charge, among other things, of sending the control data and receiving the scores from each of the stations.

\section{Station 1: Mobile Target}

Station 1 consists of a moving target, which moves on two rails, is anchored to a chain, which in turn is connected to a sprocket of an engine. In this scenario the target moves on the rails at different speeds, configurable by the user, thus allowing the user to perform his round of shots. When the target is hit, it falls and is automatically reset. It has a $24 \mathrm{~V} 4 \mathrm{~A}$ motor in charge of moving the target, two limit sensors, a $12 \mathrm{~V}$ gear motor in charge of lifting the target when it falls, a linear potentiometer that acts as a position sensor for the arm that reactivates the target and an infrared sensor that detects when the moving target falls. The block diagram of station 1 is shown in Figure 3.

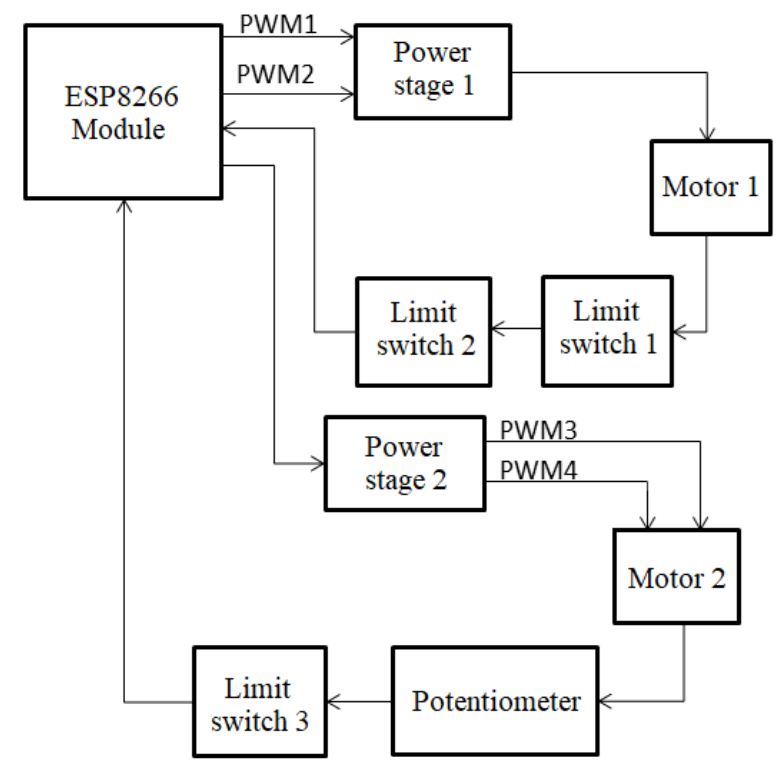

Figure 3: Block Diagram of Station 1.

When receiving data, the ESP8266 module proceeds to make around to perform the shots, depending on the speed assigned by the user from the mobile application, defining the useful cycle of PWM1 and PWM2. When the patrol is enabled, the target moves twice in both directions (from right to left and from left to right), so the PWM1 and PWM2 signals define the direction of rotation of the main DC motor (Motor 1). For the power stage in charge of moving motor 1, an H-bridge was designed with a capacity of $24 \mathrm{~V}$ at $4 \mathrm{~A}$, characteristics required by the DC motor, using a Mosfet $\mathrm{P}$ channel reference IRF9530N that has a drain current of -14A.

Two TCRT5000 reflective optical sensors were used to change the direction of rotation of motor 1 as the moving target moves in two directions. It is a sensor that includes the emitter and receiver in the same package, the module works with IR which makes it immune to visible light [8]. The infrared module acts as a limit switch for the stroke and immediately the motor reverses its rotation when it detects this signal.

To validate the speed at which the target moves, a test system was developed, where after multiple displacements in both directions, the relationship between the PWM sent by ESP8266 and the speed at which the target moves is found, this to ensure that the target moves at the speed selected by the user (Figure 4). 


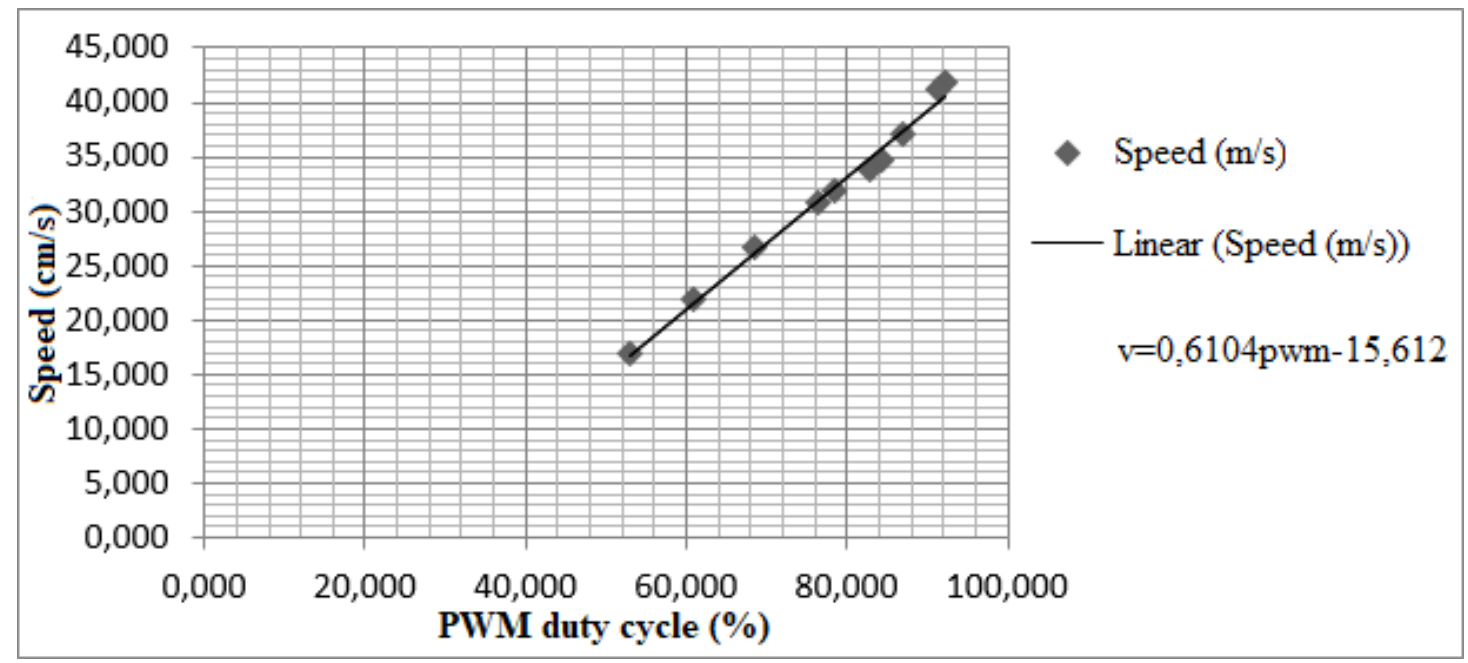

Figure 4: Speed vs. PWM Graph.

With the equation obtained, the values shown in Table 1 were selected as predefined speed values for the user to select, thus obtaining the useful cycle of the PWM for each case.

Table 1: Selected Speed Values

\begin{tabular}{|c|c|}
\hline Speed (cm/s) & PWM Duty Cycle (\%) \\
\hline $20 \mathrm{~cm} / \mathrm{s}$ & 58,34 \\
\hline $25 \mathrm{~cm} / \mathrm{s}$ & 66,53 \\
\hline $30 \mathrm{~cm} / \mathrm{s}$ & 74,72 \\
\hline $35 \mathrm{~cm} / \mathrm{s}$ & 82,91 \\
\hline $40 \mathrm{~cm} / \mathrm{s}$ & 91,10 \\
\hline
\end{tabular}

Finally, to automatically lift the target when it is knocked down, an H-bridge designed with a capacity of $18 \mathrm{~V}$ and a maximum current of $1 \mathrm{~A}$ was used, which corresponds to power stage 2 in the diagram in Figure 3 . In addition to the power stage 2, a linear potentiometer mechanically coupled to the motor shaft 2 was added as a position sensor in charge of lifting the moving target, which sends an analog signal to pin ADC0 of the ESP8266 and informs the status of the variable. Also, the infrared module TCRT5000 detects the fall of the target each time it has been hit.

\section{Station 2: Dianas}

Station 2 is composed of six discs, which are each anchored to a swing arm, every time the user hits a disc this falls, through the application the user can restart the stage by lifting the discs to start a new round of shooting. The station has a 3.3V gear motor coupled to a horizontal bar that is in charge of lifting the disks. To detect the angle at which the horizontal bar reaches, two optical sensors indicate when the bar has lifted the targets.

In the block diagram presented in Figure 5, it can be seen that after the ESP8266 module receives the data sent from the mobile application, it checks the status of the signals from two H2010 [9] horseshoe optocouplers (SA and SB sensors) and depending on their logic states it activates the Enable A (ENA) and Enable B (ENB) signals which tell the motor driver which channel to activate to give the direction of rotation to the gear motor in charge of lifting the target.

Likewise, when the motor driver channel is activated, the ESP8266 sends a PWM signal (IN1 or IN2) depending on the ordered direction of rotation. 


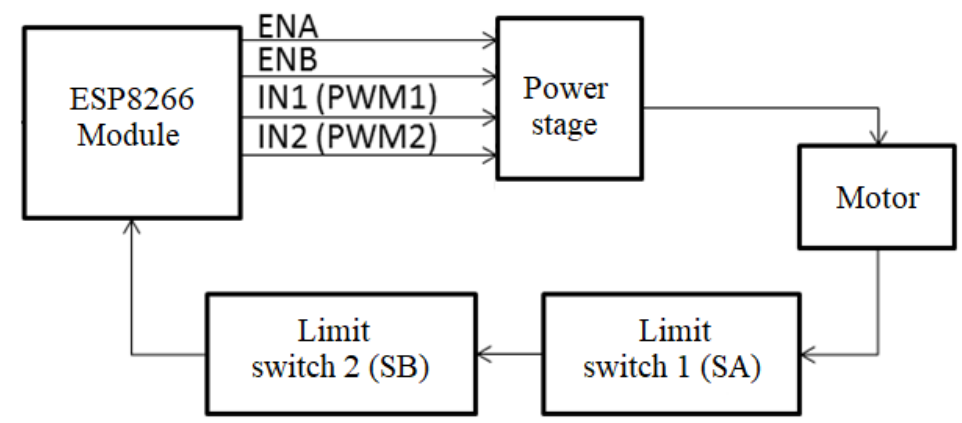

Figure 5: Block Diagram of Station 2.

\section{Station 3: Vertical Roll Targets}

Station 3 is composed of a vertical moving target roll, which is mechanically coupled to a motor and is responsible for moving target images until a limit sensor is activated so that a new target is ready to be used by the user. In this case, after the ESP8266 module receives the data sent from the mobile application, it executes the code implemented based on the flow chart presented in Figure 6.

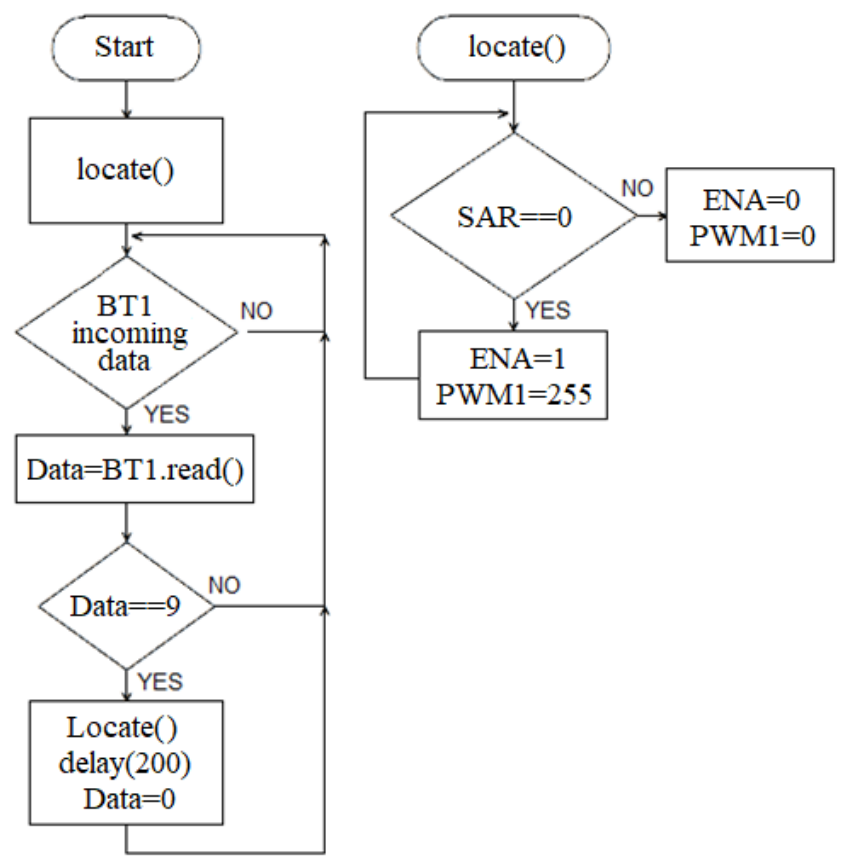

Figure 6: Flowchart of the Algorithm Implemented for Station 3.

The ESP8266 receives the signal from the H2010 horseshoe optocoupler (SAR sensors) and depending on the logic state of this sensor it activates the Enable A (ENA) signal which tells the motor driver to switch the PWM signal (IN1) to give the direction of rotation to the gear motor in charge of moving the new target until the SAR signal is activated indicating that the target is in place to be used.

\section{Blynk Application}

Blynk is a platform for IoT that allows you to control an application with a microcontroller or similar and a device with iOS or Android system, users can create a graphical interface of "drag and drop" for your project. This application is focused on different platforms: Arduino, Raspberry Pi, ESP8266, Intel Galileo, serial devices and WiFi among others [10]- 
[12]. Figure 7 shows the typical architecture of a Blynk application that allows it to operate with its server if the user requires it.

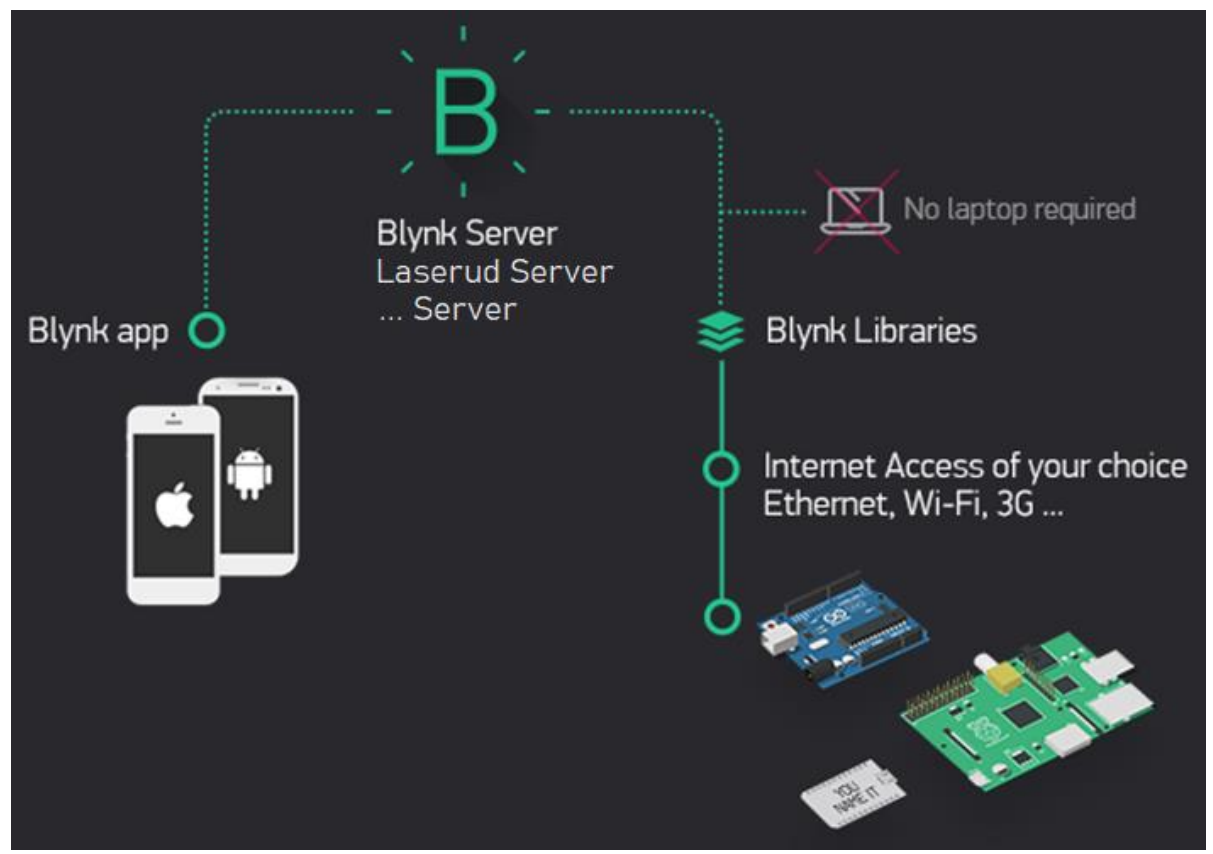

Figure 7: Typical Architecture of a Blynk Application [10].

The purpose of the application developed in Blynk is to allow the user to have easy and intuitive control of all the characteristics of the shooting range system, for this purpose the application was designed based on the flow chart shown in Figure 8. WiFi communication must be available to send and receive data between the application and each of the stations, also there must be an independent sub-menu for each of the options belonging to each scenario (moving target, target and vertical roll targets).

The process developed is summarized as follows: when executing the application, the user must send a verification request to each of the stations or scenarios (Moving Target, Diane and Vertical Roll Targets), to continue with the process each, one must generate a response indicating to the application that they are all online and operational if this does not happen the process returns to the beginning until the problem with the station or stations in conflict is solved. Then the user must select the scenario with which he wants to practice shooting among the three possible ones, each one of the stations presents a similar operation logic. When selecting Station 1 (Moving Target) the user must choose between the five possible speed values that were previously determined in the design $(20 \mathrm{~cm} / \mathrm{s}, 25 \mathrm{~cm} / \mathrm{s}, 30 \mathrm{~cm} / \mathrm{s}, 35 \mathrm{~cm} / \mathrm{s}$ and $40 \mathrm{~cm} / \mathrm{s})$, then start the round where the target moves twice from left to right and from right to left, During this round will be added the number of times the target is hit, automatically returning to its vertical position each time it falls from the impact, at the end of the round will be displayed the total score and the best score obtained so far, the process can be repeated if the user wishes. 


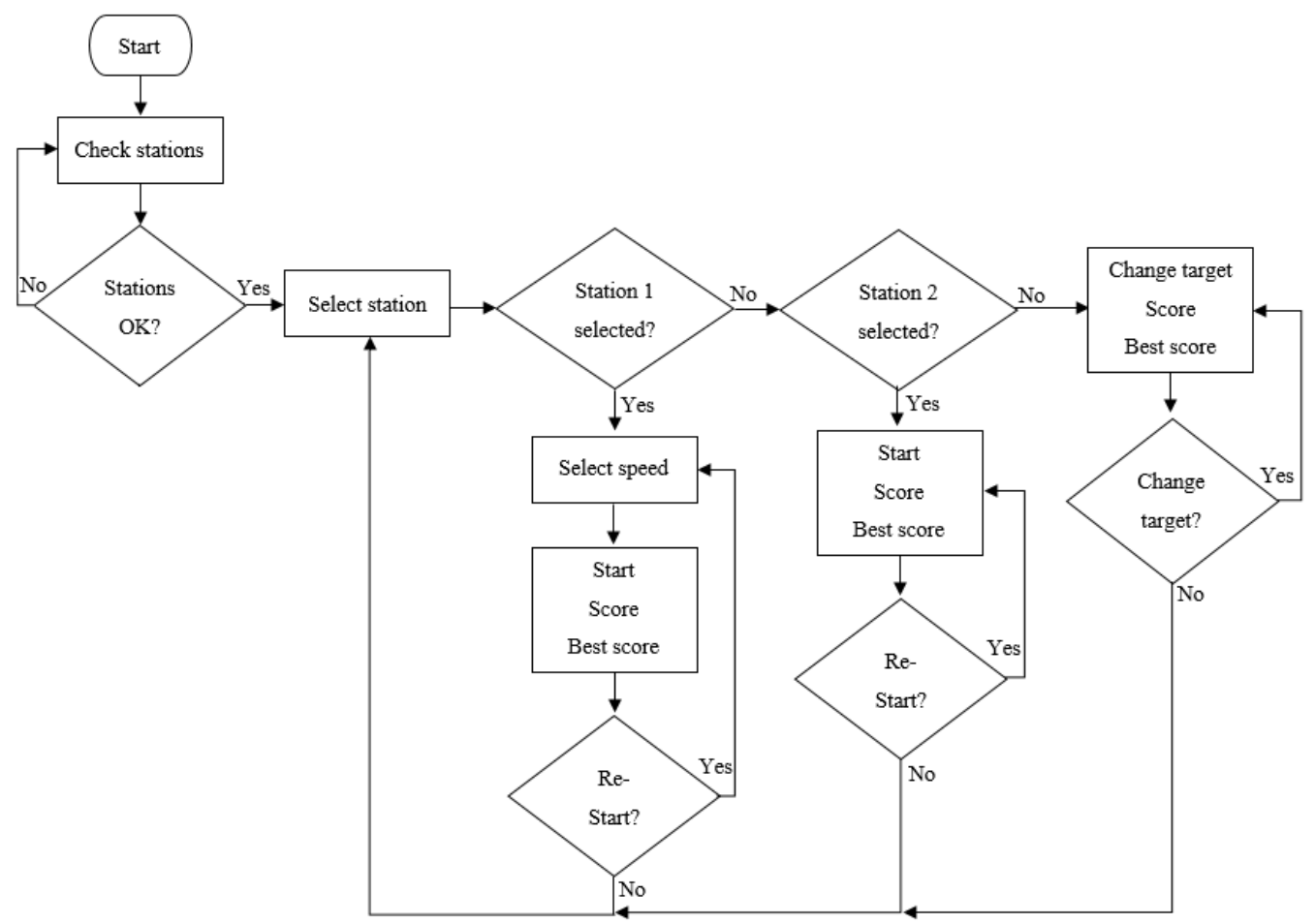

Figure 8: Blynk Application Flowchart.

For Station 2 (Dianas) the process is as follows: the user selects to start what enables the points to count every time a hit is made on any of the six targets, during the time of the round the number of times any of the targets is hit will be added up, automatically returning to its vertical position every time it is hit, at the end of the round the total score will be shown and the best score obtained so far, the process can be repeated if the user wishes.

When selecting Station 3 (Vertical Roll Targets) the user can select a new target from the available vertical roll and start the round, in this case, the score must be written manually in the application, this value is stored to be shown if it is the case as best score, the process can be repeated if the user wishes. In Figure 9 you can see the final graphic interface of the system developed in Blynk.
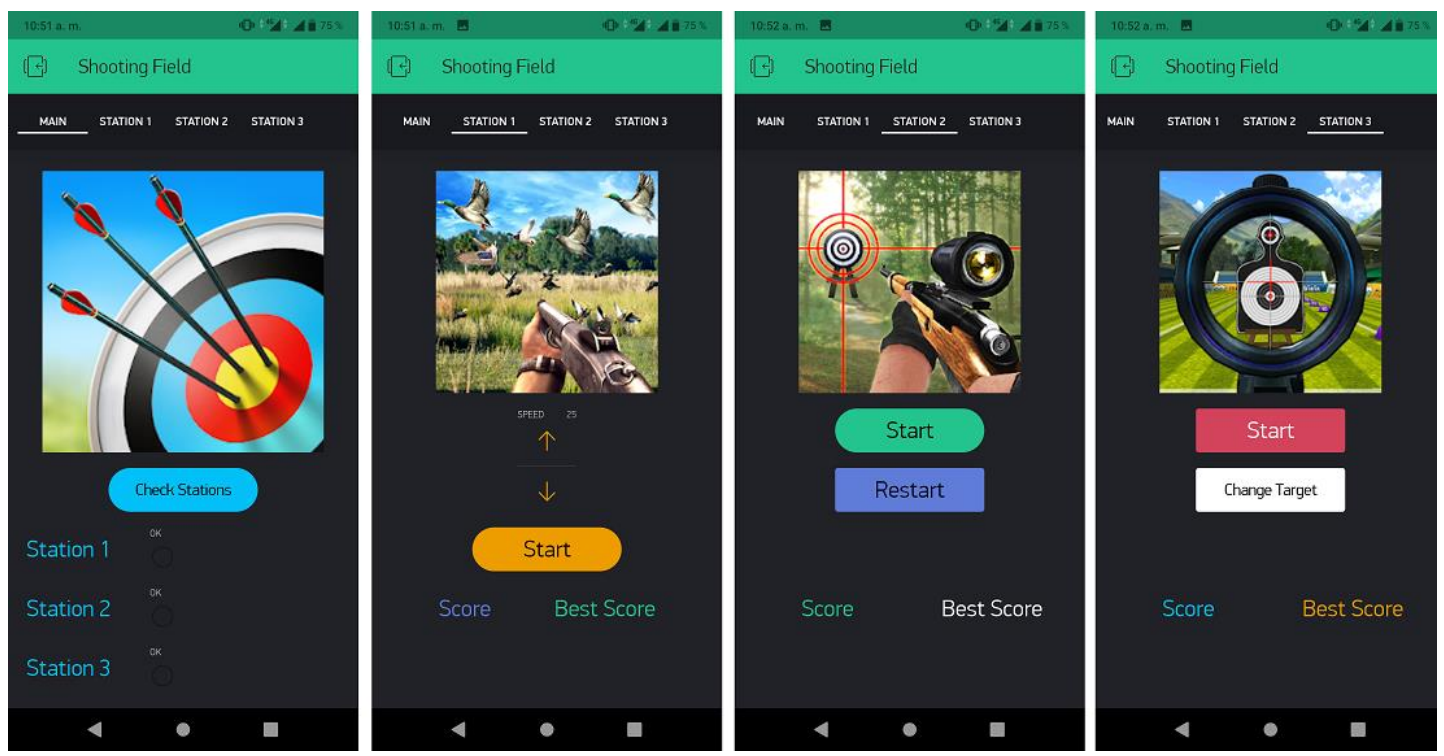

Figure 9: Graphical Application Interface. 


\section{TESTS AND RESULTS}

For the development of the system tests, the free tool WiFi Analyzer was used, which allows measuring the power of the received WiFi signal (RSSI) for each of the stations, being able to determine the relationship between distance and success rate of the communication between the mobile application and each of the stations. Table 2 shows a summary of the results obtained for each station.

Table 2: Communications Test Results for each Station

\begin{tabular}{|c|c|c|c|c|c|c|c|}
\hline \multirow{2}{*}{$\begin{array}{c}\text { Distance } \\
(\mathbf{m})\end{array}$} & \multirow{2}{*}{ View line } & \multicolumn{2}{|c|}{ Station 1 } & \multicolumn{2}{c|}{ Station 2 } & \multicolumn{2}{c|}{ Station 3 } \\
\cline { 2 - 8 } & & RSSI (dBm) & Success rate & RSSI (dBm) & Success rate & RSSI (dBm) & Success rate \\
\hline \multirow{2}{*}{5} & Yes & -49 & $100 \%$ & -48 & $100 \%$ & -49 & $100 \%$ \\
\cline { 2 - 8 } & No & -51 & $100 \%$ & -51 & $100 \%$ & -52 & $100 \%$ \\
\hline \multirow{2}{*}{10} & Yes & -55 & $100 \%$ & -55 & $100 \%$ & -56 & $100 \%$ \\
\cline { 2 - 8 } & No & -58 & $100 \%$ & -59 & $100 \%$ & -60 & $100 \%$ \\
\hline \multirow{2}{*}{20} & Yes & -60 & $100 \%$ & -61 & $100 \%$ & -62 & $100 \%$ \\
\cline { 2 - 8 } & No & -63 & $100 \%$ & -65 & $100 \%$ & -65 & $100 \%$ \\
\hline \multirow{2}{*}{50} & Yes & -70 & $100 \%$ & -69 & $100 \%$ & -70 & $100 \%$ \\
\cline { 2 - 8 } & No & -72 & $100 \%$ & -71 & $100 \%$ & -74 & $99 \%$ \\
\hline \multirow{2}{*}{100} & Yes & -79 & $100 \%$ & -78 & $100 \%$ & -79 & $100 \%$ \\
\cline { 2 - 8 } & No & -82 & $98 \%$ & -81 & $99 \%$ & -83 & $97 \%$ \\
\hline
\end{tabular}

\section{CONCLUSIONS}

The automation of a shooting range can be executed 100\% employing low-cost WiFi technology, which combined with the Android application presented is a quite striking proposal, as its main feature is the ease of interaction with the user. Additionally, the ease of programming the application allows you to modify and add configurations without further complexity.

It was possible to create a network where the minimum reliability of the link is $97 \%$ in the worst case, in which there is no line of sight. Furthermore, the functionality of the network with only three nodes was shown, which can be expanded according to the needs without having to drastically change the network topology.

\section{ACKNOWLEDGMENTS}

The authors would like to thank the Universidad Distrital Francisco José de Caldas and the LASER research group that supported the development and testing of the project.

\section{REFERENCES}

1. El Tiempo - Justicia. (2014). Uno de cada 300 colombianos tiene un arma legal. Retrieved from: http://www.eltiempo.com/politica/justicia/informe-sobre-porte-de-armas-en-colombia/14002417

2. Naciones Unidas - Oficina contra la Droga y el delito. (2006). Violencia, crimen y tráfico ilegal de armas en Colombia. Retrieved from: https://www.unodc.org/documents/lpobrazil/Topics_crime/Publicacoes/Violencia20crimen20y20trafico20ilegal20de20armas20en20Colombia2020420de20Diciembre202006.pdf

3. Secretaria del Senado de Colombia. (1993). Decreto - Ley 2535 de 1993. Retrieved from: http://www.secretariasenado.gov.co/senado/basedoc/decreto_2535_1993.html

4. Murty, A., M. Satyanarayana, and I. Devi. "Compressor Health Monitoringusing IOT." International Journal of Mechanical and Production Engineering Research and Development 8.3 (2019): 117-124. 
5. Zahir Ahmed, M., Muneer,S. A.,Waaiz, M. \& Maheswara Reddy, N. M. (2020). IoT Based Automating the Irrigation System. International Journal of Mechanical and Production Engineering Research and Development. 10(3):2515-2522.

6. Awais S., Mobeen, S., Ahmed, A., Mohsin, S. A. \&Bila, F. (2020). IoT Based Power Loom Monitoring System. International Journal of Advanced Science and Technology. 29(6s):3841-3850.

7. Narayan, Harshad, and Rijhi Dey. "A Heartbeat Detection Method Based on Iot and Monitoring System Using Arduino Uno and Thing-Speak." methods 9: 12.International Journal of Electronics, Communication \& Instrumentation Engineering Research and Development (IJECIERD) 8.3, Aug 2018, 11-16

8. Abdulahad Aziz, D. (2018). Webserver Based Smart Monitoring System Using ESP8266 Node MCU Module. International Journal of Scientific \& Engineering Research. 9(6):801-807.

9. Maddileti, T. \&Sriniha, M. (2020). Patient Monitoring System Using BLYNK App. International Journal of Advanced Science and Technology. 29(6): 1993-1998.

10. Luis Llamas - Ingeniería, informática y diseño. (2016). Detector de líneas con Arduino y sensor TCRT5000L. Retrieved from: https://www.luisllamas.es/arduino-detector-lineas-tcrt5000l/

11. Robot Store (HK).(2001). H21A1/H21A2/H21A3PHOTOTRANSISTOR Optical Interrupter Switch. Retrieved from: http://www.robotstorehk.com/H21A1.pdf

12. Hippolitus, A. Josin, and Ayush Oberoi. "Design and Development of an Iot Based Multi Terrain Humanoid Robot Foot. "International Journal of Mechanical and ProductionEngineeringResearch and Development (IJMPERD) 8. 6, Dec 2018, 143-150

13. Blynk. (2018). How does Blynk work? Retrieved from: https://blynk.io/

14. Chong Jin, L., Yusop, R. \&Ratnadurai, D. (2020). Autonomous Solar Panels Dry Cleaning System for Dust Removal using Microcontrollerand Sensors. International Journal of Advanced Science and Technology. 29(1):141-152.

15. Bombale, U L, and Sanjivani Tukaram Ikke. "Design and Implementation of Power Efficient System Using Iot Based Wireless Sensor for Environment Monitoring."International Journal of Electronics, Communication\&InstrumentationEngineeringResearch and Development (IJECIERD) 9. 1, Jun 2019, 17-24

16. Navaneethan, C. \&Meenatchi, S. (2019). Water Level Monitoring using Blynk Application in IoT. International Journal of Recent Technology and Engineering. 8(4):1676-1679. 

